\title{
ТОЧНОСТЬ СОЗДАНИЯ 3D-МОДЕЛЕЙ МАГИСТРАЛЬНЫХ ТРУБОПРОВОДОВ
}

\section{Наталья Викторовна Ланг}

Сибирский государственный университет геосистем и технологий, 630108, Россия, г. Новосибирск, ул. Плахотного, 10, обучающийся, тел. (923)137-84-16, e-mail: unforgivenn8@gmail.com

\section{Мария Михайловна Шляхова}

Сибирский государственный университет геосистем и технологий, 630108, Россия, г. Новосибирск, ул. Плахотного, 10, кандидат технических наук, доцент кафедры фотограмметрии и дистанционного зондирования, тел. (960)779-62-25, e-mail: plazma_space@mail.ru

Магистральный трубопровод является популярным методом транспортировки сырья. Протяженность трубопровода распространяется на значительные территории, что позволяет доставлять сырье во все точки. Но чтобы оно было транспортировано качественно необходимо осуществлять мониторинг состояния трубопровода, так как существуют различные риски его повреждения и образования аварийных ситуаций. В статье представлена значимость применения 3D-моделей для данного направления. Также проанализированы методы сбора информации при помощи дистанционного зондирования и выявлены наиболее подходящие в зависимости от типа объекта. Также рассмотрены пути предотвращения аварийных ситуаций путем создания 3D-моделей трубопроводов, с помощью которых выявляются потенциально опасные участки.

Ключевые слова: магистральный трубопровод, методы сбора информации, мониторинг, точность создания, лазерное сканирование, космическая съемка, защитные сооружения, 3D-модели

\section{ACCURACY OF CREATING 3D-MODELS OF MAIN PIPELINES}

\section{Natalya $V$. Lang}

Siberian State University of Geosystems and Technologies, 10, Plahotnogo St., Novosibirsk, 630108, Russia, Student, phone: (923)137-84-16, e-mail: unforgivenn8@gmail.com

\section{Maria M. Shlyakhova}

Siberian State University of Geosystems and Technologies, 10, Plakhotnogo St., Novosibirsk, 630108, Russia, Ph. D., Associate Professor, Department of Photogrammetry and Remote Sensing, phone: (960)779-62-25, e-mail: plazma_space@mail.ru

The main pipeline is a popular method of transporting raw materials. The length of the pipeline extends over large territories, which allows you to deliver raw materials to all points. But in order for it to be transported efficiently, it is necessary to monitor the condition of the pipeline, since there are various risks of damage and accidents. The article presents the significance of using 3D-models for this area. The methods of collecting information using remote sensing are also analyzed and the most suitable ones are identified depending on the type of object. We also consider ways to prevent accidents by creating 3D-models of pipelines that identify potentially dangerous areas.

Keywords: main pipeline, information collection methods, monitoring, creation accuracy, laser scanning, satellite imagery, protective structures, 3D-models 


\section{Введение}

В настоящее время нефтегазовая отрасль занимает одно из ключевых мест в экономике России. Территория страны имеет богатый потенциал сырья, который необходимо добыть, переработать и в дальнейшем транспортировать. Процесс транспортировки сырья является очень важным и может осуществляться различными способами: трубопроводным, внутренним судоходным, грузовым следует, будет зависеть от добытого объема.

Для отслеживания процесса транспортировки, исследования непосредственно протяженной части трубопровода, а также контроля за защитными сооружениями применяются 3D-модели. Точность создания 3D-моделей зависит от метода сбора данных об объекте. [1-5].

\section{Методы и материаль}

На данный момент самым востребованным и доступным способом транспортировки является трубопроводный, так как на этот способ не влияет время года, автоматизации процесса и прочее. Но также у данного метода транспортировки есть свои недостатки, к которым относится риск возникновения аварий, ведь трубопроводы могут располагаться вблизи с населенными пунктами и создавать угрозу для жизни. Поэтому необходимо создавать защитные сооружения, обеспечивающие безопасность транспортировки сырья $[6,7,8,9]$.

В табл. 1 перечислены типы объектов, к ним относятся:

- точечные - портовые комплексы;

- средние - участки подводных переходов крупных рек, крупные компрессорные и нефтеперекачивающие станции;

- линейные - трубопроводы, притрассовые ЛЭП, автодороги;

- крупные - лицензированные участки, территории месторождений.

Таблий 1

Методы сбора данных в зависимости от типа объектов

\begin{tabular}{|l|l|l|}
\hline \multicolumn{1}{|c|}{ Тип объекта } & \multicolumn{1}{|c|}{ Масштабы } & \multicolumn{1}{|c|}{ Допустимые методы сбора данных } \\
\hline Точечные & $1: 50-1: 500$ & Наземное лазерное сканирование \\
\hline $\begin{array}{l}\text { Средние площад- } \\
\text { ные }\end{array}$ & $1: 50-1: 500$ & $\begin{array}{l}\text { Наземное лазерное сканирование, воздушное } \\
\text { лазерное сканирование, радар }\end{array}$ \\
\hline Линейные & $1: 500-1: 5000$ & $\begin{array}{l}\text { Воздушное лазерное сканирование, оптико- } \\
\text { электронная космическая съемка, радарная ин- } \\
\text { терферометрия }\end{array}$ \\
\hline Крупные & $1: 10000-1: 25000$ & $\begin{array}{l}\text { Воздушное лазерное сканирование, оптико- } \\
\text { электронная космическая съемка, радарная ин- } \\
\text { терферометрия }\end{array}$ \\
\hline
\end{tabular}


Для каждого типа объектов пространственная информация может собираться различными методами (табл. 2).

Таблица 2

Методы сбора информации об объекте

\begin{tabular}{|c|c|c|}
\hline \multicolumn{2}{|c|}{ Вид съемки } & Характеристики \\
\hline \multirow[t]{2}{*}{$\begin{array}{l}\text { Лазерная } \\
\text { съемка }\end{array}$} & $\begin{array}{l}\text { Воздушное } \\
\text { сканирование }\end{array}$ & $\begin{array}{l}\text { Точность сканирования: } 8-10 \text { см } \\
\text { Соответствие масштабу: } 1: 1000\end{array}$ \\
\hline & $\begin{array}{l}\text { Наземное лазерное ска- } \\
\text { нирование }\end{array}$ & $\begin{array}{l}\text { Точность сканирования: 0,3-1,5 cм } \\
\text { Соответствие масштабу: 1:200 }\end{array}$ \\
\hline \multirow[t]{3}{*}{$\begin{array}{l}\text { Аэрофото- } \\
\text { съемка }\end{array}$} & $\begin{array}{l}\text { Цифровая фотосъемка в } \\
\text { видимом диапазоне } \\
\text { (RGB), кадровая }\end{array}$ & $\begin{array}{l}\text { Точность сканирования: } 3-30 \text { см } \\
\text { Соответствие масштабу: 1:500-1:5000. }\end{array}$ \\
\hline & $\begin{array}{l}\text { Цифровая фотосъемка в } \\
\text { ближнем ик- диапазоне } \\
(\mathrm{CIR}, \mathrm{IR}), \text { кадровая }\end{array}$ & $\begin{array}{l}\text { Точность сканирования: 10-30 см } \\
\text { Соответствие масштабу: 1:1000-1:5000. }\end{array}$ \\
\hline & $\begin{array}{l}\text { Цифровая фотосъемка в } \\
\text { тепловом диапазоне } \\
\text { (RGB), кадровая }\end{array}$ & $\begin{array}{l}\text { Точность сканирования: 20-100 см } \\
\text { Соответствие масштабу: 1:5000-1:10000. }\end{array}$ \\
\hline \multicolumn{2}{|c|}{ Космическая съемка } & $\begin{array}{l}\text { Точность сканирования: оптико-электронную } \\
\text { съемку сверхвысокого разрешения: } 30-50 \text { см, } \\
\text { Радиолокационная съемка сверхвысокого раз- } \\
\text { решения: } 1-100 \text { см } \\
\text { Соответствие масштабу: } 1: 500,1: 1000 \text {, } \\
1: 2000 \text {. }\end{array}$ \\
\hline
\end{tabular}

Таким образом, проанализировав данные табл. 1 и 2, можно сделать вывод, что целесообразнее осуществлять сбор информации о магистральных трубопроводах методом лазерного сканирования или космической съемкой. Следует отметить, что метод лазерного сканирования является самым инновационным, который позволяет спрогнозировать объекты с максимальной точностью. В космической съемке можно отметить, радиолокационную съемку, которая имеет значительные преимущества над оптико-электронной, так как не зависит ни от уровня освещенности, ни от погоды, а значит, что данные факторы никак не могут сказаться на качестве получаемого изображения.

\section{Результаты}

Существует две основные причины, по которым возникают аварии магистральных трубопроводов: внутренние и внешние. К внутренним факторам повреждений относят коррозию, а к внешним - какие-либо механические повреждения. Поэтому, чтобы избегать аварийных ситуаций, необходимо проводить мониторинг трубопроводов, выявлять такие места и устанавливать защитные сооружения [8, 10-13]. Задачами защитных сооружений при перекачке сырья является защита нефтепровода от влияния различных факторов. 
Защитные сооружения можно разделить на два типа в зависимости от строительного материала: земляные и инженерные. В зависимости от материала 3Dмодели защитных сооружений могут создаваться с определенной точностью: земляные сооружения в плане и по высоте 15 см, бетонные сооружения 15 мм.

Таким образом, зная точность создания защитных сооружений и методов съемки можно с максимальной точностью создавать 3D-модели, чтобы своевременно выявлять потенциально опасные участки трубопроводов и снижать риск возникновения аварий.

Полученную информацию можно использовать для создания 3D-моделей, которые помогут своевременно выявлять возникшие чрезвычайные ситуации, следить за надежностью трубопровода, осуществляя его мониторинг в течение всего периода эксплуатации [14-16]. Также 3D-модели позволяют отслеживать изменения и автоматически моделировать ситуации в трехмерной форме участка деформации. Таким образом, применение 3D-моделей, позволяет $[17,18]$ :

- производить автоматические замеры геометрических параметров коммуникации;

- осуществлять контроль за транспортировкой, добычей сырья;

- обновлять информацию на основе данных об изменении местности;

- проводить мониторинг состояния коммуникаций;

- моделировать аварийные ситуации по материалам различных датчиков (давление, температура) и предотвращать их.

\section{Заключение}

Подводя итоги, можно отметить, что транспортировка сырья осуществляется различными способами, но трубопроводный до сих пор является наиболее выгодным и безопасным способом. Чтобы не допускать аварийных ситуаций необходимо производить 3D-мониторинг, используя методы дистанционного зондирования, и на основании полученной информации осуществлять построение 3D-моделей с максимальной точностью и детальностью. С помощью таких моделей выявляются и анализируются проблемы на участках трубопровода с целью их быстрой ликвидации.

Работа выполнена в рамках государственного задания Минобрнауки России (тема «Разработка теории и технологических решений контроля состояния защиттных сооружений при перекачке нефтепродуктов методами активного дистанционного зондирования», № 0807-2020-0002).

\section{БИБЛИОГРАФИЧЕСКИЙ СПИСОК}

1. Hausamann, D. Monitoring of gas transmission pipelines - a customer driven civil UAV application, 2010. URL: https://www.researchgate.net/publication/241543602_Monitoring_of _gas_pipelines_-_A_civil_UAV_application.

2. Statistical Review of World Energy 2020, 69th edition. URL: https://www.bp.com/content/dam/bp/business-sites/en/global/corporate/pdfs/energyeconomics/statistical-review/bp-stats-review-2020-primary-energy.pdf. 
3. Гук А. П. Фотограмметрия и дистанционное зондирование : учебник. Новосибирск : СГУГиТ, 2018. - 248 с.

4. Гук А. П., Шляхова М. М. Аэрокосмические съемки : учеб. пособие. Новосибирск : СГУГиТ, 2019. - 105 с.

5. ДД3 в Нефтегазовом комплексе съемки [Электронный ресурс] // Иннотер. Геопространственное агентство. URL: https://innoter.com/otraslevye-resheniya/neftegazovyy-kompleks/.

6. Жуков Б. Н. Геодезический контроль сооружений и оборудования промышленных предприятий: монография. - Новосибирск: СГГА, 2003. - 356 с.

7. Кузьмина, Е. С. Анализ причин возникновения чрезвычайных ситуаций на объектах хранения нефти и нефтепродуктов / Е. С. Кузьмина, В. В. Варнаков // Modern Science. - 2019. № 4(1). - С. 379-383.

8. О структуре системы физической защиты магистральных трубопроводов от преднамеренных угроз / В. А. Комаров, 3. В. Семенова, Д. А. Бронников, А. А. Нигрей // Вестник ПНИПУ. Геология. Нефтегазовое и горное дело. - 2019. - Т. 19, №1. - С. 87-100.

9. Перспективы применения аэросъемок для контроля состояния защитных сооружений магистральных трубопроводов / М. М Шляхова, В.В. Дедкова // Сборник трудов конференции. Региональные проблемы дистанционного зондирования земли. - 2020. -С. 316 - 319.

10. Мониторинг нефтеразливов [Электронный ресурс] // Совзонд. URL: https://sovzond.ru/industry-solutions/oil-gas/monitoring-nefterazlivov/.

11. Мониторинг трубопроводов, контроль состояния трубопроводов [Электронный ресурс] // Смис Эксперт URL: https:/www.smis-expert.com/pages/uslugi/proektirovanie/monitoringtruboprovodov.html.

12. Нефтегазовая отрасль и использование радиолокационной съемки [Электронный ресурс] // Иннотер. Геопространственное агентство. URL: https://innoter.com/articles/ispolzovanieradiolokatsionnoy-semki-v-neftegazovoy-otrasli/.

13. Хасенова, Д. Ф. Возможности применения методов аэрокосмического мониторинга для обнаружения утечек из нефтегазопроводов // Технические науки: теория и практика: материалы I Междунар. науч. конф. (г. Чита, апрель 2012 г.). - Чита : Издательство Молодой ученый, 2012. - С. 135 - 139.

14. Комаров, В. А. О структуре системы физической защиты магистральных трубопроводов от преднамеренных угроз [Текст] / В. А. Комаров, 3. В. Семенова, Д. А. Бронников, А. А. Нигрей // Вестник ПНИПУ. Геология. Нефтегазовое и горное дело. - 2019. - Т. 19, №1. C. 87-100.

15. Минкин, Д. Ю. Космический тепловизионный мониторинг нефтегазопроводного транспорта / Д. Ю. Минкин, С. Н. Терехин, А. П. Корольков, Ш. А. Османов // Пожаровзрывобезопасность . - 2017. - Т. 26, №12. - С. 45-51.

16. Минкин, Д. Ю. Космический тепловизионный мониторинг нефтегазопроводного транспорта / Д. Ю. Минкин, С. Н. Терехин, А. П. Корольков, Ш. А. Османов // Пожаровзрывобезопасность / Fire and explosion safety. - 2017. - Т. 26, №12. - С. 45-51.

17. Разработка методик создания 3D-моделей по аэрокосмическим снимкам высокого и сверхвысокого разрешения и другим данным дистанционного зондирования / А.П. Гук, М. М Шляхова // Известия высших учебных заведений. Геодезия и аэрофотосъемка. -2011. №2 - C. 32-34.

18. Геоинформационная модель мониторинга технического состояния трубопроводов нефтегазового комплекса / А.В. Комиссаров, Л.К Радченко // Интерэкспо Гео-Сибирь. - 2014. №2. - C. 44 -48. 